\title{
Text, Performance, and Gender in Chinese Literature and Music
}

\section{Essays in Honor of Wilt Idema}

\author{
Edited by \\ Maghiel van Crevel \\ Tian Yuan Tan \\ Michel Hockx
}

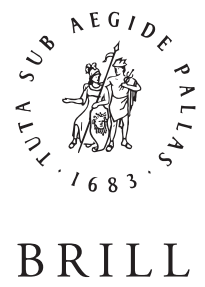

LEIDEN • BOSTON

2009 


\title{
RETHINKING LI KAIXIAN'S EDITORSHIP OF REVISED PLAYS BY YUAN MASTERS: A COMPARISON WITH HIS BANTER ABOUT LYRICS
}

\author{
Tian Yuan Tan
}

In the late 1550s and 1560s, the mid-Ming literatus Li Kaixian 李開先 (1502-1568) became particularly interested in printing Yuan dynasty $q u$ 曲 (literally “songs," including both sanqu 散曲 and drama) and was involved in a number of projects. ${ }^{1}$ Li's interest in these publishing projects was supported by his own stupendous book collection, which he claimed exceeded ten thousand juan. ${ }^{2}$ The thirty existing Yuan-dynasty editions of Yuan plays, which have been critical to our understanding of the textual transmission of zaju 雜劇, are also believed to have been part of Li's collection at one time. ${ }^{3}$

\footnotetext{
${ }^{1}$ For biographical studies of Li Kaixian, see Bu Jian 卜鍵, Li Kaixian zhuanlüe 李開先傳略 (A Brief Biography of Li Kaixian) (Beijing: Zhongguo xiju chubanshe, 1989); Iwaki Hideo 岩城秀夫, “Ri Kaisen nempu” 李開先年譜 (A Chronological Biography of Li Kaixian), Mimei, no. 8 (1989): 63-106; Niu Ruzhang 牛汝章 et al., eds., Li Kaixian nianpu 李開先年譜 (Zhangqiu: Zhengxie Zhangqiu xian wenshi ziliao yanjiu weiyuanhui, 1990); Zeng Yuanwen 曾遠聞, Li Kaixian nianpu 李開先年 譜 (Ji'nan: Qilu shushe, 1991); and Li Yongxiang 李永祥, Li Kaixian nianpu 李開 先年譜 (Ji'nan: Huanghe chubanshe, 2002). See also the chapter on Li Kaixian in Yagisawa Hajime 八木澤元, Mindai gekisakka kenkyū 明代劇作家研究 (Studies on Ming Dynasty Playwrights) (Tokyo: Kōdansha, 1959), esp.172-244, Chinese translation in Mingdai juzuojia yanjiu 明代劇作家研究, trans. Luo Jintang 羅錦堂 (Hong Kong: Longmen shudian, 1966), 145-207. For a brief introduction to Li in English, see L. Carrington Goodrich and Chaoying Fang, eds., Dictionary of Ming Biography (New York: Columbia University Press, 1976), 835-837.

${ }^{2}$ Li proudly named his library the "Library of Ten Thousand Fascicles," and made it clear that the actual size of his book collection exceeded ten thousand juan. He also added that this particular library only held books on the classics and statecraft, and that he kept books on other subjects elsewhere. See Li Kaixian, "Cangshu wanjuan lou ji” 藏書萬卷樓記 (On the Library of Ten Thousand Fascicles), in Li Kaixian quanji 李開先全集, ed. Bu Jian (Complete Works of Li Kaixian, hereafter LKXQJ) (Beijing: Wenhua yishu chubanshe, 2004), 826.

${ }^{3}$ Iwaki Hideo, “Genkan kokon zatsugeki sanjūshu no ryūden” 元刊古今雜劇三十 種の流傳 (The Transmission of the Thirty Ancient and Recent Zaju Printed in the Yuan Dynasty), in Chügoku kotengeki no kenkyū (Tokyo: Sōbunsha, 1986), esp. 565-570.

For a comprehensive discussion of the various editions of Yuan drama and the
} 
From his collection of Yuan drama, it was known that Li Kaixian had printed a number of the plays in an anthology titled Gaiding Yuanxian chuanqi 改定元賢傳奇 (Revised Plays by Yuan Masters, hereafter GDYXCQ):

Now, the poems and prose of the Han and Tang dynasties cover and fill the entire world, and the various books of Song Neo-Confucianism are also widely transmitted, but Yuan songs are rarely seen. What we see are often just ordinary works, or the remains of rouge and powder. For example, Wang Shifu 王實甫 is not the greatest among the writers of the Yuan dynasty; Xixiang ji 西廂記 (The Story of the Western Chamber) is also not the most outstanding among his writings throughout his lifetime. Yet now, even the ladies and young girls can quote his verses. Does this not show that in human life, there is fortune and misfortune? Anthologies such as Erduan jin二段錦 (Two Pieces of Brocade), Siduan jin 四段錦 (Four Pieces of Brocade), Shiduan jin 十段錦 (Ten Pieces of Brocade), Baiduan jin 百段錦 (A Hundred Pieces of Brocade), Qianduan jin 千段錦 (A Thousand Pieces of Brocade), and Qianjia jin 千家錦 (Brocade of a Thousand Households) include both good and bad, and are all mixed up without proper order. The anthologies of short songs and song suites are also mostly like these. I regarded this as a shortcoming, and I wished that people in this age would get to see the Yuan-dynasty songs and realize how the Yuan songs have achieved their reputation. Thus I disclosed completely the more than one thousand copies that I keep, and gave them to my disciple Zhang Zishen 張自慎 (courtesy name Cheng'an 誠㟟) to choose. Only fifty were selected. It was beyond my ability to put all of them into print, so from these, we made a further selection of sixteen. We deleted superfluous sections to make the texts simple and concise, changed the rhymes and corrected the sounds. Wherever a tune did not fit, a line was not proper, or the dialogues were not to the point and too vague, we edited and corrected all of them. We even wrote some passages on behalf of the original authors. Therefore, we named this publication Revised Plays by Yuan Masters. ${ }^{4}$

importance of the thirty Yuan dynasty printings, see Wilt L. Idema, "Why You Never Have Read a Yuan Drama: The Transformation of Zaju at the Ming Court," in Studi in onore di Lanciello Lanciotti, ed. S.M. Carletti, M. Sacchetti, and P. Santangelo (Napoli: Istituto Universitario Orientale, Dipartimento di Studi Asiatici, 1996), 765-791, and Stephen H. West, "Text and Ideology: Ming Editors and Northern Drama," in The Song-Yuan-Ming Transition in Chinese History, ed. Paul Jakov Smith and Richard von Glahn (Cambridge, MA: Harvard University Asia Center, 2003), 329-373.

${ }^{4}$ Li Kaixian, “Gaiding Yuanxian chuanqi xu”《改定元賢傳奇》序 (Preface to GDYXCQ), LKXQJ, 461. Cf. translation in Wilt L. Idema, "Li Kaixian's Revised Plays 
The preface to GDYXCQ makes clear that Li Kaixian produced this collection of Yuan plays out of dissatisfaction with the existing compilations, which he felt were mediocre. In GDYXCQ he aimed to provide readers with a collection that would truly represent the charm of Yuan drama. Furthermore, as reflected in its title, Li claimed that the texts in the resulting collection were revised and improved.

Known to be the earliest Ming anthology of Yuan plays and hence significant for the study of the transmission of Yuan zaju texts, it is no surprise that GDYXCQ has long held the attention of scholars. Yet for decades, GDYXCQ remained an enigmatic collection whose whereabouts eluded twentieth-century scholars. It was long believed that GDYXCQ was likely kept in Taiwan, until it was made known recently that the collection is actually kept in the Nanjing Library. ${ }^{5}$

Earlier studies, written when scholars were still unsure where GDYXCQ was kept and therefore did not get to see the text, made various assumptions about the collection. As we will see below, many expected GDYXCQ to be textually closely related to, or share similar features with, other extant printing projects of Yuan arias produced by Li Kaixian. This expectation of a "common text" among the various projects was clearly based on the assumption that Li was actively involved in all these projects and that he applied the same criteria and editorial rigor to all of them, including GDYXCQ.

Even some of the scholars who have recently gained access to GDYXCQ continue to believe that Li Kaixian participated arduously in the project. The editor of the new critical edition of Li's complete works claims that $\mathrm{Li}$ "put his heart and soul" into GDYXCQ and that this project reflects Li's criteria in selecting and editing Yuan drama. ${ }^{6}$

These claims and assumptions all suggest that the collection was carefully prepared by Li Kaixian. But do the drama texts in GDYXCQ support these claims and assumptions? Did Li indeed play such a significant role in editing the collection?

In this paper, I will first show that GDYXCQ is far from systematic in its revisions and editorial conventions, and discuss what this

by Yuan Masters (Gaiding Yuanxian chuanqi) and the Textual Transmission of Yuan Zaju as Seen in Two Plays by Ma Zhiyuan," CHINOPERL Papers, no. 26 (2006): 50.

${ }^{5}$ Xie Yufeng 解玉峰, “Du Nantu guancang Li Kaixian Gaiding Yuanxian chuanqi” 讀南圖館藏李開先《改定元賢傳奇》 (Reading Li Kaixian’s GDYXCQ in the Collection of the Nanjing Library), Wenxian, no. 2 (2001): 158-169. The existing edition is kept in the Nanjing Library (Number 115015).

${ }^{6}$ See Bu Jian's introductory notes to GDYXCQ, LKXQJ, 1701-1702. 
suggests with regard to the editorial process of this collection. Next, by placing GDYXCQ alongside Li Kaixian's other printing projects, I aim to reconsider the role he played as an editor. As the arias of a few plays in GDYXCQ are also included in his Cixue 詞謔 (Banter about Lyrics), I will compare the relevant arias as they are preserved in the two works, both supposedly edited by $\mathrm{Li}$, in order to assess his actual involvement in the editing of GDYXCQ.

\section{GDYXCQ As a Collection: OBSERvations and IMPLICATIONS}

According to the preface, Li Kaixian had intended to print sixteen plays in GDYXCQ, but its extant edition preserves only six plays, each in a single juan. ${ }^{7}$ They are now available in a photographic reprint in the Xuxiu Siku quanshu 續修四庫全書 (Continued Complete Writings from the Four Storehouses [hereafter XXSKQS]) series, and in a modern typeset edition. ${ }^{8}$

The six plays are Ma Zhiyuan's 馬致遠 (ca. 1250-before 1324) Qingshan lei 青衫淚 (Tears on a Blue Gown) and Chen Tuan gaowo 陳摶高臥 (Chen Tuan Rests on High [at Xihua Mountain]), Qiao Ji's 喬吉 (ca.1280-1345) Yangzhou meng 揚州夢 (Yangzhou Dream), Bai Pu’s 白樸 (1227-1306) Wutong yu 梧桐雨 (Rain on the Wutong Tree), Qiao Ji's Liangshi yinyuan 兩世姻緣 (Marriage in Two Lives), and Wang Ziyi's 王子一 (late Yuan to early Ming) Wuru Tiantai 誤入天 台 ${ }^{9}$ (Entering Mount Tiantai by Mistake). All six plays are complete

7 We have no clues as to which are the remaining plays originally selected for this collection and which Li believed would be a balanced and more comprehensive representation of what Yuan drama was about.

Xie Yufeng points out that only sixty-six plays were constantly selected in the Wanli editions of Yuan drama (excluding YQX), and suggests that this might have been influenced by the original selection of fifty plays for GDYXCQ. See Xie, "Du Nantu guancang Li Kaixian Gaiding Yuanxian chuanqi," 164. If so, GDYXCQ would have played a major part in shaping the anthologizing of Yuan plays, but unfortunately extant sources do not allow us to investigate this possibility.

${ }^{8}$ See XXSKQS (Shanghai: Shanghai guji chubanshe, 1995-1999), vol. 1760, 109188. For a typeset edition of the six plays, see LKXQJ, 1701-1808. A drawback of this typeset edition is that it arranges the plays in a different order and makes changes to the text to make it conform to the later Ming editions, in both content and form. Thus, for all references to GDYXCQ, I use the photographic reprint in the XXSKQS edition.

${ }^{9}$ Here, I follow a more common simplified title of the play. The simplified title as marked in the block center (banxin 版心) of this play in GDYXCQ, however, is Liu Ruan Tiantai 劉阮天台. 
except for the first, Tears on a Blue Gown, from which the first full page is missing.

These six plays are preserved in other Ming editions too, and therefore none of the plays in GDYXCQ are "new" in the sense of previously unknown or undiscovered. The significance of GDYXCQ is that it provides us with an early example of how Yuan dramatic texts were printed and transmitted.

In the last few years, scholars such as Xie Yufeng 解玉峰, Akamatsu Norihiko 赤松紀彥 and Wilt Idema have looked more carefully at the textual characteristics and significance of GDYXCQ.${ }^{10}$ Xie Yufeng has pointed out that, in general, GDYXCQ is textually close to the majority of Wanli editions of Yuan drama other than Zang Maoxun's 藏森 循 (1550-1620) Yuan qu xuan 元曲選 (Selected Yuan Plays, hereafter $Y Q X)$. He observes that "wherever GDYXCQ differs from YQX, the other Ming editions also differ from YQX." ${ }^{11}$ Based on such textual affinities, Xie cautiously concludes that GDYXCQ and the Ming editions may have derived from a common source, or that the later Ming editions were influenced by or derived directly from GDYXCQ. ${ }^{12}$

GDYXCQ's textual affinities with the other Ming anthologies can be well illustrated by studying the arrangement of songs in the third act of Marriage in Two Lives. The modern scholar Zheng Qian 鄭騫, in comparing the existing Ming editions of the play (other than GDYXCQ), points out that except for Zang's YQX and Meng Chengshun's 孟稱舜 (1598-1684) later Gujin mingju hexuan 古今名劇合選 (A Collective Selection of Famous Plays Old and New), which was influenced by

10 See Xie, "Du Nantu guancang Li Kaixian Gaiding Yuanxian chuanqi," 158169; Akamatsu Norihiko, "Gaiding Yuanxian chuanqi xiaokao-Chen Tuan gaowo yu Qingshanlei”《改定元賢傳奇》小考——《陳摶高臥》與《青衫淚》(A Brief Study of GDYXCQ: On Chen Tuan Rests on High and Tears on a Blue Gown), in Zhongguo xiju: cong chuantong dao xiandai, ed. Dong Jian and Rong Guangrun (Beijing: Zhonghua shuju, 2006), 149-156; and Idema, "Li Kaixian's Revised Plays by Yuan Masters," 47-65.

${ }^{11}$ Xie, "Du Nantu guancang Li Kaixian Gaiding Yuanxian chuanqi," 163.

${ }_{12} \mathrm{Ibid}$. The difference of opinions on the textual relationship between GDYXCQ and the other Ming editions may also be related to individual appraisals of the extent of changes the editors of GDYXCQ made to its source texts. Akamatsu believes GDYXCQ followed its sources in most cases. See Akamatsu, "Gaiding Yuanxian chuanqi xiaokao," 156. Idema, however, suggests that GDYXCQ made substantial changes to its source texts especially in providing stage directions and dialogues. His detailed comparison of the Yuan edition and the GDYXCQ edition of Chen Tuan gaowo convincingly demonstrates the changes between the Yuan edition and GDYXCQ. See Idema, "Li Kaixian's Revised Plays by Yuan Masters," 51-55. 
$Y Q X$, all other Wanli editions had two tune titles mixed up in Act Three. ${ }^{13}$ Since its rediscovery in the Nanjing Library, we know that GDYXCQ contains the same mistake. ${ }^{14}$

The failure to correct the tune titles (assuming that GDYXCQ followed its source text in this case) calls into question Li Kaixian's grand statement in his preface that GDYXCQ presents to us an improved version of the Yuan plays in which mistakes were corrected and texts were polished. Furthermore, there is reason to believe that the collection did not follow a strict and standardized format in editing. This can be supported by looking at some of the "irregularities" in its formal characteristics.

Among the six plays anthologized in GDYXCQ, five mark act divisions, which reflects a new trend in drama printing of the time..$^{15}$ This is, however, not the earliest case of such a practice, because we already find such markings of act division in the 1498 edition of The Story of the Western Chamber. Tears on a Blue Gown is the only play in GDYXCQ in which act division is not clearly marked, a feature that is associated with the Yuan editions and earlier Ming printings. ${ }^{16}$

Now, let us look at another irregular feature in GDYXCQ, the marking of the "wedge" ( $x i e z i$ 楔子). Of the five plays that contain a wedge, only three mark the wedge: Tears on a Blue Gown, Rain on the Wutong

In order to say that the changes were first introduced in GDYXCQ, we have to make the assumption that there were no intermediary texts between the Yuan edition and GDYXCQ. I am more inclined to believe that GDYXCQ might possibly share common source texts with other Ming anthologies. Also, as I will argue in the discussion that follows, GDYXCQ should not be taken as a collection with a well-defined set of editorial rules, and could have been compiled by different individuals not necessarily sharing the same attitude towards editing. This might further complicate the textual relationship between GDYXCQ and other Wanli editions.

${ }_{13}$ The two tunes whose titles were confused are Shengyaowang 聖藥王 and Tusi'er 秃㸖兒. See Zheng Qian, “Yuan zaju yiben bijiao (Di si zu)” 元雜劇異本比較（第四 組) (A Comparison of the Variant Texts of Yuan Zaju: Group 4), in Guoli bianyiguan guankan 5, no. 1 (1976): 12.

${ }^{14}$ Marriage in Two Lives, 20a-21b, in XXSKQS, 171.

${ }_{15}$ While five of the six plays mark their Acts Two, Three, and Four, none of the six mark the first act. Xie Yufeng also notes that Marriage in Two Lives differs from the other plays in that it marks the acts without the ordinalizing prefix $d i$ 第. See Xie, "Du Nantu guancang Li Kaixian Gaiding Yuanxian chuanqi," 166.

${ }^{16}$ The style of drama printing in the early Ming is demonstrated by the plays of Zhu Youdun 朱有燉 (1379-1439) and also the 1435 edition of Jintong yunü jiaohongji 金 童玉女嬌紅記 (Golden Page and Jade Maiden: The Story of Jiaoniang and Feihong). See Wilt L. Idema, The Dramatic Oeuvre of Chu Yu-tun (1379-1439) (Leiden: Brill, 1985), 35-38. 
Tree, and Entering Mount Tiantai by Mistake. ${ }^{17}$ Where the wedges are marked, they are consistently placed under the tune title and do not include any prose dialogue. Sun Kaidi 孫楷第 has pointed out that the wedge should only refer to songs and did not include dialogues, and did not serve as a kind of demi-act as presented in later anthologies most noticeably in $Y Q X .{ }^{18}$ Therefore, inasmuch as the wedges are marked in GDYXCQ, this followed the older practice of using it to mark one or two songs that are not part of a main suite for any act.

However, the wedge is not marked in all of the plays in GDYXCQ. Two other plays, Yangzhou Dream and Marriage in Two Lives, contain the arias of a wedge but do not mark them as such, ${ }^{19}$ which would appear to follow an even earlier practice that we find in Yuan editions. Scholars have argued, based on the feature of act division, that Tears on a Blue Gown perhaps preserves an older format than the other five plays. ${ }^{20}$ Here, however, Tears on a Blue Gown marks the wedge, which is a later feature, while the other two plays appear to follow the old practice. This provides further evidence that these features were not standardized in GDYXCQ. How might such irregularities be related to the manner in which the collection was put together?

\section{A Reconsideration of Li Kaixian's Role: COMPARING GDYXCQ WITH BANTER ABOUT LYRICS}

We have learnt from Li Kaixian's preface to GDYXCQ that he served as the sponsor of this project, and provided the drama texts from his own collection for selection. However, Li mentioned that his disciple

17 Tears on a Blue Gown, 7b, Rain on the Wutong Tree, 6a, and Entering Mount Tiantai by Mistake, 13b, in XXSKQS, 112, 149, and 182 respectively.

${ }^{18}$ Sun Kaidi, "Yuan qu xinkao" 元曲新考 (New Studies on $Q u$ of the Yuan Dynasty), in idem, Cangzhouji (Beijing: Zhonghua shuju, 1965), 321-324.

${ }_{19}$ See Yangzhou Dream, 3a, in XXSKQS, 136, and Marriage in Two Lives, 2b, in XXSKQS, 162.

${ }^{20}$ Xie, "Du Nantu guancang Li Kaixian Gaiding Yuanxian chuanqi,"167, and Akamatsu, "Gaiding Yuanxian chuanqi xiaokao," 152. Idema has also suggested that at the very end of Tears on a Blue Gown, the editors of GDYXCQ maintained a peculiar feature that may be used as yet another argument that this edition of the play derived from a Yuan dynasty printing: the coda of the final suite is followed by the text of a lyric to the tune of Zhegutian 麃鴣天 which is not assigned to any character in the play, a practice found only in the Yuan printing of Shi Junbao's 石君寶 Ziyun ting 紫雲庭 (Purple Cloud Pavilion). See Idema, "Li Kaixian's Revised Plays by Yuan Masters," 61-65. 
Zhang Zishen was also involved. Who else participated in the editorial process? And if there was a group of people working on this project, do we know what role Li actually played in the editing of GDYXCQ?

For answers to these questions, we have to turn to the postface to the collection, also by Li Kaixian:

Those who took part in the editing and making the changes also included the three lyricists Gao Bifeng [i.e. Gao Yingqi], Mi Shao'an [i.e. Mi Zifang], and Zhang Weidu. But the man who was with the project from its beginning to its completion was Cheng'an [i.e. Zhang Zishen]. To make an analogy: in editorial projects, there is always a Director-General ${ }^{21}$ and there are Compilers; at examinations, there is an Examiner and there are Assistant-Examiners. And I have only acted as Director-General and the Examiner. ${ }^{22}$

Under Li's sponsorship and "direction"-more symbolic than actual, as I will argue-as Director-General, we find an editorial committee of sorts, formed by his students and acquaintances. Zhang Zishen, ${ }^{23}$ in particular, appears to have been the most involved in the project, to the extent that one Qing-dynasty catalog lists GDYXCQ under Zhang's name. ${ }^{24}$

Zhang was a native of Shanghe in Shandong. He was a stipend student before his writings criticizing the court were discovered, and he had to flee from arrest. He escaped to Zhangqiu, Li Kaixian's home village, where he stayed for around ten years and later became Li's student. ${ }^{25}$ Zhang's expertise in northern $q u$ was highly praised. ${ }^{26} \mathrm{He}$

${ }^{21}$ Zongcai 總裁, which refers to a "duty assignment for an eminent official to preside over an editorial project" or the like. See Charles O. Hucker, A Dictionary of Official Titles in Imperial China (Stanford: Stanford University Press, 1985), 534.

${ }^{22} \mathrm{Li}$ Kaixian, “Gaiding Yuanxian chuanqi houxu" 《改定元賢傳奇》後序 (Postface to GDYXCQ), LKXQJ, 462. Cf. translation in Idema, "Li Kaixian's Revised Plays by Yuan Masters," 49.

${ }_{23}$ Zhangqiu xianzhi 章邱縣志 (Gazetteer of Zhangqiu County), 1691 edition, in Qingdai guben fangzhi xuan (Beijing: Xianzhuang shuju, 2001), series 1, vol. 3, juan 6, "Liuyu" 流寓 (Residents in Foreign Lands), 46b-47a.

${ }^{24}$ See Qianqingtang shumu 千頃堂書目 (Catalog of Books in the Qianqing Hall), juan 32, cited by Yagisawa Hajime, Mindai gekisakka kenkyū, 247.

${ }^{25}$ See Yu Shenxing's 于慎行 poem titled “Zeng Zhang Jiushan yinju” 贈張就山 隱居, cited in Tan Yuancai 譚源材 et al., eds., Shandong yishu fazhanshi yanjiu 山東 藝術發展史研究 (A Study of the History of Development of the Arts in Shandong) (Beijing: Zhongguo guangbo dianshi chubanshe, 1992), 33. Li Kaixian often referred to Zhang as "my student" (menren 門人).

${ }^{26}$ Comments by Wan Boxiu 萬伯修 cited in Wang Shizhen 王士禎, Chibei outan 池北偶談 (Casual Talks by the North Side of the Pond) (Beijing: Zhonghua shuju, 1982), 337. 
was also apparently a prolific playwright known to have written more than thirty $z a j u$, but unfortunately all these plays have been lost. ${ }^{27}$

Also involved in the project of GDYXCQ was Li Kaixian's other student Gao Yingqi 高應玘 (courtesy name [ $z i$ 字] Bifeng 筆峰, fl.1540s) ${ }^{28}$ whom Li referred to as a young member in his local qu writing club. ${ }^{29}$ In Gao's sanqu collection titled Zuixiang xiaogao 醉鄉小稿 (A Small Manuscript in My Drunkenness), we find that a substantial part of his writings were occasional songs written for fellow members, such as a xiaoling 小令 congratulating Li Kaixian on the birth of his son. ${ }^{30}$ In addition, Gao was also the author of a zaju which is no longer extant. ${ }^{31}$ Other members of the editorial team include Zhang Weidu 張畏獨 ${ }^{32}$ and Mi Zifang 弭子方 ${ }^{33}$ (courtesy name Shao'an 少菴), about whom we know very little.

These individuals all played a part in the process of editing and emending the texts for GDYXCQ. That various people were involved in the editorial process may have contributed to the non-systematic marking of features such as act divisions and the wedge, as discussed earlier. Such irregularities in the text also show that Li was apparently not too particular about these details.

Hence, even though Li Kaixian claimed final responsibility for GDYXCQ, calling himself its Director-General, I submit that in fact his involvement in the printing project of GDYXCQ may well have been minimal. Li mentioned in his preface to GDYXCQ that after this

27 Zhangqiu xianzhi, juan 6, "Liuyu," 46b-47a.

${ }^{28}$ For brief biographies of Gao, see Zhangqiu xianzhi, juan 6, 41a-b, and Zhongguo $x i q u z h i$ 中國戲曲志 (Gazetteers of Chinese Theater) (Beijing: Zhongguo ISBN zhongxin, 1994), vol. 27 Shandong 山東, 693-694.

${ }^{29}$ Li Kaixian, “Zuixiang xiaogao xu” 《醉鄉小稿》序 (Preface to A Small Manuscript in My Drunkenness), LKXQJ, 418. This preface was not found in the extant copy of Zuixiang xiaogao kept in the National Library of China (Number 17575), which only carries a preface written by Gao himself, dated 1553. On Li's local qu writing club in Zhangqiu, see Tian Yuan Tan, Qu Writing in Literati Communities: Rediscovering Sanqu Songs and Drama in Sixteenth-Century North China (PhD dissertation, Harvard University, 2006), Chapter Three.

${ }^{30}$ Gao Yingqi, Zuixiang xiaogao, copy kept in the National Library of China (Number 17575), $1 \mathrm{~b}$.

${ }^{31} \mathrm{Fu}$ Xihua 傅惜華, Mingdai zaju quanmu 明代雜劇全目 (A Complete Catalog of Ming Zaju) (Beijing: Zuojia chubanshe, 1958), 110.

${ }^{32}$ We have no information about Zhang Weidu. He is not mentioned elsewhere in Li Kaixian's writings.

${ }_{33}$ Both Mi Zifang and Li Kaixian married daughters of Zhang Qi. Mi also wrote a colophon for Li's literary collection and was involved in its compilation. See Mi, "Mi Zifang ba” 弭子方跋 (Colophon by Mi Zifang), LKXQJ, 390-391. 
collection of Yuan drama, he wished to continue printing song suites and xiaoling if at all possible. ${ }^{34} \mathrm{He}$ did indeed pursue these goals with his subsequent printings of the song collections of Yuan masters Zhang Kejiu 張可久 (1280-after 1348), and Qiao Ji in the winter of 1566 and in the spring of 1567 respectively. ${ }^{35}$ In addition, he also included a selection of Yuan-dynasty song suites in his treatise on qu titled Banter about Lyrics. ${ }^{36}$

While all these may be considered as Li Kaixian's qu printing projects in general, a comparison between GDYXCQ and these other projects revealed that Li was not equally involved in all of them. The "Citao" 詞套 (Song Suites) section of Li's Banter about Lyrics is especially important in this respect. ${ }^{37}$ It contains a selection of arias from three

${ }^{34}$ Li Kaixian, “Gaiding Yuanxian chuanqi xu," LKXQJ, 461.

${ }^{35}$ See Li Kaixian comp., Zhang Xiaoshan xiaoling 張小山小令 (Short Songs by Zhang Xiaoshan [Zhang Kejiu]), Ming edition kept in the Taiwan National Library (14979), and idem, comp., Qiao Mengfu xiaoling 喬夢符小令 (Short Songs by Qiao Mengfu [Qiao Ji]), Ming edition kept in the Taiwan National Library (Number 14985). For Li's views on the sanqu of these two Yuan-dynasty writers, see Yang Dong 楊棟, Zhongguo sanquxue shi yanjiu (xubian) 中國散曲學史研究（續編）(A Study of the History of Scholarship on Sanqu in China: Supplementary Volume) (Ji'nan: Shandong daxue chubanshe, 1998), 112-116.

${ }^{36}$ Banter about Lyrics is a rare example of dramatic criticism written in northern China in the mid Ming. It contains four different sections: amusing and satirical stories behind some $q u$ works, a selection of sanqu and dramatic arias, anecdotes about famous actors and singers, and a discussion on the proper endings of $q u$.

$37 \mathrm{Wu}$ Shuyin 吳書蔭 has proposed that the second and fourth sections, “Citao" and “Ciwei” 詞尾 (Song Endings), may have been written by Kang Hai 康海 $(1475-1541)$ instead of Li Kaixian. His argument is based on the fact that Xu Fuzuo 徐復祚 (1560-?) quoted the same passages in these two sections in his qu anthology, but attributed them to Kang rather than Li. See Wu Shuyin, "Cixue de zuozhe xianyi”《詞謔》的作者獻疑 (Calling into Question the Authorship of Banter about Lyrics), Yishu baijia, no. 2 (2002): 67-70.

However, considering that the section "Citao" cites Tang Shunzhi 唐順之 and Chen Shu 陳束, who were closely associated with Li and not Kang, I believe it is unlikely that these sections were compiled and written by Kang Hai. Wu also believes that Xu Fuzuo is unlikely to have made a wrong attribution, as he was already nine years old when Li Kaixian passed away, but such errors in attribution were perhaps not uncommon even among contemporaries. One example is Wang Shizhen 王世貞 (1526-1590), who was acquainted with Li but still inaccurately noted that Kang Hai thought highly of Li's one hundred xiaoling. See Wang Shizhen, Quzao 曲藻 (Evaluations of Qu), in Zhongguo gudian xiqu lunzhu jicheng (Beijing: Zhongguo xiju chubanshe, 1959, 1980 reprint), vol. 4, 36. Kang had passed away by the time Li wrote these hundred songs in 1544, and it was Wang Jiusi 王九思 (1468-1551) instead who praised Li's songs.

Recently, Huang Shizhong 黄仕忠 has also refuted Wu Shuyin's argument and reaffirmed Li Kaixian's authorship of Banter about Lyrics. See Huang, "Cixue zuozhe quewei Li Kaixian-yu Wu Shuyin xiansheng shangque”《詞謔》作者確為李 
of the six plays in GDYXCQ, namely Yangzhou Dream, Rain on the Wutong Tree, and Marriage in Two Lives. ${ }^{38}$ In other words, we have a number of overlapping arias that appear in both GDYXCQ and Banter about Lyrics, which we can use for comparison.

It is unclear which of the two projects, GDYXCQ or Banter about Lyrics, was completed earlier. We have little information on the date of GDYXCQ. Assuming that the Ten Pieces of Brocade mentioned by $\mathrm{Li}$ in his preface is the extant 1558 edition we now have, we can only estimate that GDYXCQ was printed after $1558 .{ }^{39}$ Nor do we know exactly when Li wrote the "Citao" section of his Banter about Lyrics, though the full work is believed to have been put together in his late years (and left uncompleted when he passed away in 1568). ${ }^{40}$ However, the dating of these two projects is not the main point here. Our main concern is to find out whether Li Kaixian was personally involved in both projects and whether GDYXCQ and Banter about Lyrics are textually related.

Zheng Qian, writing at a time when the whereabouts of GDYXCQ were still not widely known, suggested that the arias in Banter about Lyrics, which showed some differences from other Ming editions, were probably derived from the texts in GDYXCQ edited also by Li Kaixian. ${ }^{41}$ Similarly, Lin Fengxiong 林鋒雄 has speculated that GDYXCQ would

開先一與吳書蔭先生商榷 (The Author of Banter about Lyrics is Truly Li Kaixian: Taking Issue with Mr. Wu Shuyin), Yishu baijia, no. 1 (2005): 74-78, and 84.

38 Acts One and Two of Yangzhou Dream, Act Two of Rain on the Wutong Tree, and Act Three of Marriage in Two Lives. See Li Kaixian, Cixue, in Zhongguo gudian xiqu lunzhu jicheng series, vol. 3, 344-346 and 348-350, 337, and 304-306.

${ }^{39}$ Iwaki Hideo, "Genkan kokon zatsugeki sanjūshu no ryūden," 561, and Xie, "Du Nantu guancang Li Kaixian Gaiding Yuanxian chuanqi," 162. A recent study on character usage in GDYXCQ also shows that the extant edition was printed no earlier than the late years of the Jiajing (1522-1567) reign. See Sato Haruhiko 佐藤晴彥, “Gaiding Yuanxian chuanqi de chuban shiqi”《改定元賢傳奇》的出版時期 (The Publishing Date of GDYXCQ), in Zhongguo fei wuzhi wenhua yichan, no. 11 (2006): 1-9.

$\mathrm{Bu}$ Jian believes that it was later, around 1566, that $\mathrm{Li}$ and his assistants started editing these Yuan plays, but did not provide any supporting evidence. See Bu Jian's introductory notes to GDYXCQ, LKXQJ, 1701. Bu's dating may be based on the assumption that GDYXCQ was completed not long before Li Kaixian involved himself in the printing of the sanqu by Zhang Kejiu and Qiao Ji as announced in his preface.

${ }^{40}$ It was said that Li's inability to complete the Banter about Lyrics was among his regrets as laid out in his handwritten will before his death. See "Xian Taichang nianpu," 先太常年譜 (Chronological Biography of Our Ancestor, Vice Minister of the Court of Imperial Sacrifices), in LKXQJ, 1885

${ }^{41}$ Zheng Qian, “Yuan zaju yiben bijiao (Di er zu)” 元雜劇異本比較（第二組） (A Comparison of the Variant Texts of Yuan Zaju: Group 2), in Guoli bianyiguan guankan 2, no. 3 (1973): 111. 
likely be textually closely related to Banter about Lyrics, and would demonstrate editorial principles identical to those of the latter. ${ }^{42}$

Now that we have access to the texts of the six plays in GDYXCQ, we realize that this is not the case. The arias of the same plays as they appear in GDYXCQ and Banter about Lyrics are by no means identical. It is impractical to provide full collation notes here, but some of the major differences should suffice to illuminate the textual relationship or lack thereof between GDYXCQ and Banter about Lyrics.

In some cases, the differences are extensive. For example, some songs might be left out in a song suite in one version of a play, but not in the other. The most striking example is Banter about Lyrics's selection of the song suite in Act Two of Rain on the Wutong Tree, which is shorter than that in GDYXCQ. Arias to the tunes of Mantingfang 滿庭芳 and Putianle 普天樂 are included in GDYXCQ, but do not appear in Banter about Lyrics. ${ }^{43}$ Zheng Qian has pointed out that qu anthologies such as Shengshi xinsheng 盛世新聲 (New Tunes from a Prosperous Age), Cilin zhaiyan 詞林摘艷 (Beauty Plucked from the Forest of Lyrics) and Yongxi yuefu 雍熙樂府 (Songs of Harmonious Peace) all show such discrepancies, and therefore believes that $\mathrm{Li}$, in editing this song suite in Banter about Lyrics, might have based his text on a common source used by these anthologies. ${ }^{44}$

Furthermore, we have observed earlier that in Act Three of Marriage in Two Lives, the GDYXCQ version mixes up the exact same two tune titles as a number of other Ming editions. Such errors are not found in Banter about Lyrics. ${ }^{45}$

How can we explain these differences between the texts of the same plays in two projects supposedly both edited by Li Kaixian? Can we say that one is an improved or corrected version of the other? In the case

${ }^{42}$ Lin Fengxiong, "Li Kaixian yu Yuan zaju: Jianlun Mingdai Jiajing Longqing nianjian Yuan zaju zhi yanchang yu liuchuan," 李開先與元雜劇——兼論明代嘉 靖隆慶年間元雜劇之演唱與流傳 (On Li Kaixian and Yuan Zaju, with a Discussion on the Performance and Transmission of Yuan Zaju during the Jiajing and Longqing Reigns in the Ming Dynasty), in idem, Zhongguo xiju shi lungao (Taibei: Guojia chubanshe, 1995), 53-54.

${ }^{43}$ Cf. Rain on the Wutong Tree, 16a-17a, in XXSKQS, 154, and Cixue, 338.

${ }^{44}$ See Zheng Qian, "Yuan zaju yiben bijiao" (Group 2), 113. However, in other cases, for example in Rain on the Wutong Tree, the version in Banter about Lyrics differs from that in the anthology Songs of Harmonious Peace. Hence, we cannot assume that Songs of Harmonious Peace was a source consistently used by Li in editing these song suites.

${ }^{45}$ Cf. Marriage in Two Lives, 20a-b, in XXSKQS, 171, and Cixue, 305. 
of Marriage in Two Lives, one may be tempted to speculate that Banter about Lyrics corrected the mistakes in GDYXCQ, assuming that it was compiled later than GDYXCQ. However, the earlier example of Rain on the Wutong Tree does not support this hypothesis, since in that play it is actually the version in Banter about Lyrics that shows discrepancies not found in GDYXCQ. It is clear from these two examples that we do not find mistakes in one project consistently corrected in the other. ${ }^{46}$ Contrary to speculations in earlier studies, we must therefore conclude that textually, these two projects are not systematically related, and that neither can possibly have been derived from the other.

Finally, let us turn to Yangzhou Dream, a play for which we find less extensive differences between the GDYXCQ and Banter about Lyrics versions. Prior to the rediscovery of GDYXCQ, when scholars compared the other Ming editions of the play, they concluded that the version in Gumingjia zaju 古名家雜劇 (Ancient Zaju by Famous Authors, hereafter GMJZJ) is very similar to that in Banter about Lyrics. ${ }^{47}$ This statement now needs to be revised. A comparison of the three versions reveals that GDYXCQ is textually much closer to GMJZJ than to Banter about Lyrics. In instances where the GMJZJ version differs from Banter about Lyrics, we find that the GDYXCQ version demonstrates the same variants in identical fashion. This is evident in the minor variants throughout the first two acts of the play, and more prominently so in the arias of the tune Qingge'er 青歌兒 in Act One.48

In sum, Banter about Lyrics and GDYXCQ present to us two different "texts" belonging to separate systems. ${ }^{49}$ Notably, moreover,

${ }^{46}$ We are also unable to make generalizations about variants between Banter about Lyrics and GDYXCQ. For example, in terms of padding words to the arias, the Banter about Lyrics version of Marriage in Two Lives has fewer padding words than the GDYXCQ version, but for Yangzhou Dream and Rain on the Wutong Tree, it has more padding words than the GDYXCQ version. Therefore, we cannot conclude which edition has, in general, added or deleted the padding words. It may be because they were based on different source texts, or because individual plays in GDYXCQ underwent different degrees of editing.

${ }^{47}$ This is in comparison with another group of texts in Yuan Ming zaju 元明雜劇 (Zaju from the Yuan and Ming Dynasties) and in the anthology Songs of Harmonious Peace. See Zheng Qian, “Yuan zaju yiben bijiao” (Group 4), 7, and Komatsu Ken 小松 謙, Chügoku koten engeki kenkyū 中國古典演劇研究 (A Study of Chinese Classical Drama) (Tokyo: Kyuko shoin, 2001), 214.

${ }^{48}$ Cf. the GMJZJ version in Guben xiqu congkan 古本戲曲叢刊 (Collective Edition of Ancient Texts of Plays), Fourth Series (Shanghai: Shangwu yinshuguan, 1958), 6b7a, the GDYXCQ version, 8a-b, in XXSKQS, 138, and Cixue, 346.

${ }^{49}$ In general, the later Ming editions differ from Banter about Lyrics in the way that GDYXCQ did. In other words, while GDYXCQ was very similar to the Wanli 
Li Kaixian neither referred to nor showed awareness of differences between respective versions of the same plays in GDYXCQ and in Banter about Lyrics. This makes it extremely unlikely that Li should have been the actual editor of both projects. I therefore submit that they should be seen as two separate editorial efforts, and that Li was not equally active in both.

We have Li Kaixian's own words accounting for his emendations to the arias selected in Banter about Lyrics. For example, Li explicitly points out that he has made changes to the suite of songs he selected from the second act of Rain on the Wutong Tree, because he noticed rhyme errors in the sources on which his edition was based. ${ }^{50}$ For GDYXCQ, however, one must remember that Li only called himself Director-General in the editing of the collection and credited most of the actual editorial work to Zhang Zishen and others. Indeed, Li might have only served as a sponsor and a supplier of the texts for selection. His disciple, Zhang Zishen - who was, as noted, himself a prolific playwright - might have been the de facto editor.

Li Kaixian appears to have left the GDYXCQ project to his disciples, and quite evidently was not as actively involved in the editorial process of these plays as he was in the selection and emendation of song suites for Banter about Lyrics. Therefore, GDYXCQ should be taken as a collective group effort of Li's local qu community in Zhangqiu, and we should be cautious about Li's actual editorial role and general involvement in it. To understand Li's criteria and efforts in editing Yuan zaju, we should instead turn to Banter about Lyrics as the more reliable source-and more generally, as a rich source for the study of both sanqu and drama that awaits further exploration.

editions, the arias in Banter about Lyrics appear to present a different "text" that was apparently not taken up by the later Ming editions.

${ }^{50} \mathrm{Li}$, Cixue, 337. 